\title{
Multiscale Organization of Landscape Structure in the Middle Taiga of European Russia
}

\begin{abstract}
Dominant landscape-ecological models either focus on the hierarchical organization of a single phenomenon or describe relations at a single hierarchical level. We proposed the tool MALS (Multiscale Analysis of Landscape Structure) to reveal multiple independent hierarchies based on the interactions between properties of relief, soils and vegetation and tested it on the example of the middle-taiga landscape in European Russia. Morphological properties of soils and abundance of plant species were measured in operational territorial units. Multidimensional scaling was used to reveal ecological drivers. Combinations of landforms from DEM were used to describe spatial heterogeneity in the higher-order geosystems. Response surface regression was applied to relate soils and vegetation to each other and to relief of several hypothetic higher-order geosystems. Spatial extent of a higher-order geosystem was determined from the series of equations. Then we compared contributions of external (inter-level) and internal (intra-level) interactions to spatial variability of soils and vegetation. Herbs, low shrubs, and morphologic soil properties turned out to be controlled mainly by the geosystems with the linear size $1200 \mathrm{~m}$, while trees, shrubs, and sediments - by the geosystems with size $2000 \mathrm{~m}$. From 2 to 5 levels of the higher-order geosystems should be considered in order to obtain the proper explanation of spatial heterogeneity.
\end{abstract}

\author{
Alexander V. Khoroshev* \\ Lomonosov Moscow State \\ University, Faculty of Geography, \\ Russia \\ *Corresponding author: \\ Alexander V. Khoroshev, Lomonosov \\ Moscow State University, Faculty of \\ Geography, Leninskiye Gory 1, RUS- \\ 119991 Moscow, Russia, \\ Email: avkh1970@yandex.ru
}

\section{Keywords:}

Scale, hierarchy, geocomponent, interaction, response surface regression, neighborhood, landform, emergent effect 


\section{Introduction}

The Interest in the multiscale organization of landscapes is encouraged by the necessity to translate information among hierarchy levels (O'Neill 1988; Wu \& David 2002; Burnett \& Blaschke 2003; Zhang et al. 2013). The key idea of the concept is that each property of a landscape reflects the superposition of effects generated at various hierarchical levels. Hierarchy theory suggests that multiple scales of pattern will exist in landscapes because of the multiple scales at which processes are acting (Turner \& Gardner 2015). Since landscape-ecological studies traditionally focus on the linkages between both natural geocomponents (e.g. bedrock, soil, water, air, vegetation, animals) and spatial units it is crucial to reveal interactions between spatial and nonspatial effects. Limitations upon the interactions between geocomponents are imposed by the differences both in characteristic space scale and time scale inherent to phenomena and processes. Characteristic time was defined as the span of time during which particular processes occur or, in the case of self-regulating systems, the time required for a system to return to a state of equilibrium (Armand \& Targul'yan 1976). Theoretically, interactions can occur only between those natural phenomena that have comparable time and space scales (Delcourt et al. 1983; Puzachenko 1986; Shugart 1999). To avoid uncritical application of the famous metaphor "everything is linked to everything" the concept of partial geocomplexes, or partial geosystems, was developed in physical geography (Neef 1967, Sochava 1978, Solon 1999) as a tool to consider strong linkages between groups of certain properties with similar space and time scales.

The definition of landscape as a geosystem is adopted mainly by physical geographers and landscape ecologists (Bastian et al. 2015). Solnetsev (1948) defined landscape as a "genetically uniform territory, with regular and typical repetition of some interrelated combinations of geological structures, landforms, surface and groundwater, microclimates, soil types, phytocoenoses and zoocoenoses". Geosystems form hierarchies but the specific spatial and temporal scales at which interrelationships operate must be recognized. A hierarchy is defined as a system of interconnections wherein the higher levels constrain the lower levels to various degrees, depending on time constraints of the behavior (Turner \& Gardner 2015). Since scale multiplicity is inherent in spatial heterogeneity multiscale analysis is imperative for understanding the structure, function and dynamics of landscapes (Wu et al. 2000).

The studies of multiscale organization of landscapes in recent decades has relied upon the concepts of general system theory, theory of complex adaptive systems, hierarchy theory (Carlile et al. 1989; Vasconcelos et al. 1993; Haila 2002; Perry \& Enright 2002; Hall et al. 2004; King et al. 2004; Yao et al. 2006; Cushman 2016). Evidences for the multiplicity of scales affecting ecological processes were found on the examples of dead wood patterns and dynamics (Kennedy et al., 2008), spatial patterns of vegetation in wetlands (King et al. 2004), variability of soil properties and processes (Kachanoski 1988), soil humidity as a factor of plant cover pattern (Lookingbill \& Urban 2004), influence of topographybased hydrologic features on patterns of woody plant encroachment in savanna landscapes (Wu \& Archer 2005), shrub-encroachment due to ecogeomorphic feedbacks (Turnbull et al. 2010), spatial shifts of alpine treelines (Zeng \& Malanson 2006), the relationship between the forest vegetation and relief (Chang et al. 2006), the linkage between runoff and vegetation in semiarid landscapes (Wilcox et al. 2003), chemical soil properties as related to soil biomass in mountainous tundra (Oline \& Grant 2002), soil attributes across an alpine topographic/snow gradient (Litaor et al. 2002), species distribution in connection to position in a landscape (Fletcher et al. 2016).

The most critical issue in multiscale landscape studies is the quantitative evaluation of the contributions from each scale level to the spatial variability of landscape attributes (Borcard \& Legendre 2002; Cushman \& McGarigal 2002; Yao et al. 2006; Khoroshev et al. 2007). To compare the contributions of ecological non-spatial and spatial factors a number of techniques have been applied involving autocorrelation, canonical ordination, 
Fourier-analysis, and general additive mixed modeling (Lookingbill \& Urban 2004; Legendre 1993; Couteron et al. 2006; Musio et al. 2007; Cross \& Perakis 2011).

The most commonly used concept that relates pattern to process in landscape ecology, the patchcorridor-matrix model, perceives the landscape as a planimetric surface (Hoechstetter et al. 2008). The need to include vertical dimension to landscape pattern models requires consideration for the role of topographic and geological structures (Bolstad et al. 1998; Dorner et al. 2002; Sebastiá 2004; Khoroshev \& Aleshchenko 2008; Dragut et al. 2010; Bastian et al. 2015). The focus on the critical significance of abiotic environment in shaping landscape structure has been instrumental for the Central and East European schools in landscape ecology and physical geography, even since the earliest stages (Berg 1915; Solnetsev 1948; Neef 1967; Angelstam et al. 2013; Bastian et al. 2015). The landscape's relief can be interpreted in various ways: (i) as a legacy of former-time processes (e.g. sedimentation in Pleistocene), (ii) as an indicator of geological structure affecting nutrient supply and (iii) as a binding factor for the present-day matter flows (e.g. erosion, water migration, seeds dispersion etc.). The patterns in a landscape surface that are of interest to landscape ecologists may also be interpreted as emergent properties of particular combinations of surface heights and slopes across the study area (McGarigal \& Cushman 2005). Weaver \& Perera (2004) criticized the models simulating the fate of each pixel independently (termed pseudospatially explicit by Malanson 1996) and argue that accounting for the spatial dependence create more reliable output for analyzing spatial patterns and relating those patterns to ecological processes.

The purpose of our research was to evaluate the contributions of the emergent effects generated within the higher-order geosystem and the effects of internal interactions within the focus-level geosystem. Correlating properties of soil and vegetation were hypothesized to vary in space within the constraints imposed by combination of landforms in some neighborhood. As McGarigal et al. (2016) wrote, determining the right neighborhood size is a major focus of current multiscale habitat selection modeling. We argue that the statistically significant relations within a set of correlating soil-vegetation properties as well as the spatial patterns of the higher-order geosystems may indicate the present-day or former-time processes that govern spatial heterogeneity. According to Malanson et al. (2017), for the analysis of changes in scale, two approaches are common: multilevel (defined as including multiple hierarchical levels of observation in a single model) and multiscale (multiple extents in separate analyses). In this paper, the multiscale analysis is performed to explain the soil-vegetation relationships at the focus level by the processes operating at the higher level of landscape organization. The dominant landscape-ecological models focus either on hierarchical organization of one natural geocomponent (in most cases plant cover, land use or relief, which can be easily detected from DEM and satellite imagery) or describe relations at a single hierarchical level. In contrast, we propose the tool to reveal multiple independent hierarchies based on the interactions between properties of natural geocomponents. If the rule that relates geocomponents to each other is uniform across the entire space of a heterogeneous geosystem, this indicates the emergent property. To prove the existence of such a rule one needs to express the interdependency between geocomponents by any statistically significant quantitative model for a spatial series of landscape units (Khoroshev \& Aleshchenko 2008). By this we test the hypothesis as follows: if the combination of spatial units in some neighboring area changes, the properties of the focus unit will change as well (Khoroshev et al. 2007). The size of a neighboring area that affects processes in a focus unit is a matter of analysis. Hence, we face the need to compare the quality of statistical models designed for several hypothetic higher-order geosystems. Thus, the paper focuses on statistical and cartographic methods that could provide answers to the following questions: How to evaluate the contributions to spatial variability created by radial interactions between natural geocomponents and those imposed by higher-order geosystems? How to range the spatial and nonspatial factors affecting low-order landscape units? 


\section{Materials and methods}

\subsection{Study area}

The research was performed in the middle taiga of East-European plain (the southern Arkhangelsk region of Russia) between $60.83 \mathrm{~N}-60.94 \mathrm{~N}$ and 43.00E - 43.38E (Fig. 1). The study area (the Zayachya river basin, $154 \mathrm{~km}^{2}$ ) is located within the Ustyanskoye plateau and composed of Permian sedimentary rocks. Elevations range from 100 to 175 $\mathrm{m}$ a.s.l. Physical environment of the landscape was shaped by morainic and limnoglacial accumulation in the Riss period of the Pleistocene. Flow directions of the first- and second- order streams are affected strongly by the system of lineaments stretching northeastward and northwestward (Khoroshev 2003). Development of the Zayachya terraces with alluvial deposits overlaying Permian marlstones and morainic loams dates back to the late Würm (Avessalomova et al. 2016).

Humus accumulation in soils indicates high content of base cations due to close to surface carbonate morainic loams or Permian marlstone, in most cases - on the valley slopes. Podzolization develops on the poorer substrates where loams are covered by $30-$ $70 \mathrm{~cm}$ thick sandy layer deposited in the Pleistocene glacial lakes. Peat accumulation occurs mainly in the oligotrophic mires at the central sections of the flat interfluve areas. Pinetum eriophoro-sphagnosum communities on Histic Gleysols or Histosols on the flat interfluves are gradually replaced by Piceetum myrtillosum forests on Haplic Podzols and further towards the valley slopes - by Piceetum oxalidosum forests on Umbrisols or Rhendzic Leptosols. In the secondary forests Populus tremula dominates after clear-cutting on the most nutrient-rich soils, Betula pendula - on the soils with medium nutrients supply, and Pinus sylvestris - on the poorest soils with thick sandy layer. During recovery succession all of them are replaced by Picea abies, except for the units on sandy terraces where pine preserves its domination.

\subsection{Data}

Field data were collected at 184 forested sample plots 20×20 m distributed relatively evenly across the Zayachya river basin in accordance with proportions of various landforms (flat interfluves, slopes, terraces, floodplains), and variety of succession stages, water and nutrients supply level. At each plot we described landforms (genesis, shape, slope angle, aspect), soil and vegetation cover. Phytocoenosis was described by 5 groups of attributes: abundance of species in the layers of trees (10 variables), shrubs (10 variables), low shrubs (9 variables), herbs (50 variables) and mosses (4 variables). Soils were characterized by three groups of attributes: thickness of genetic

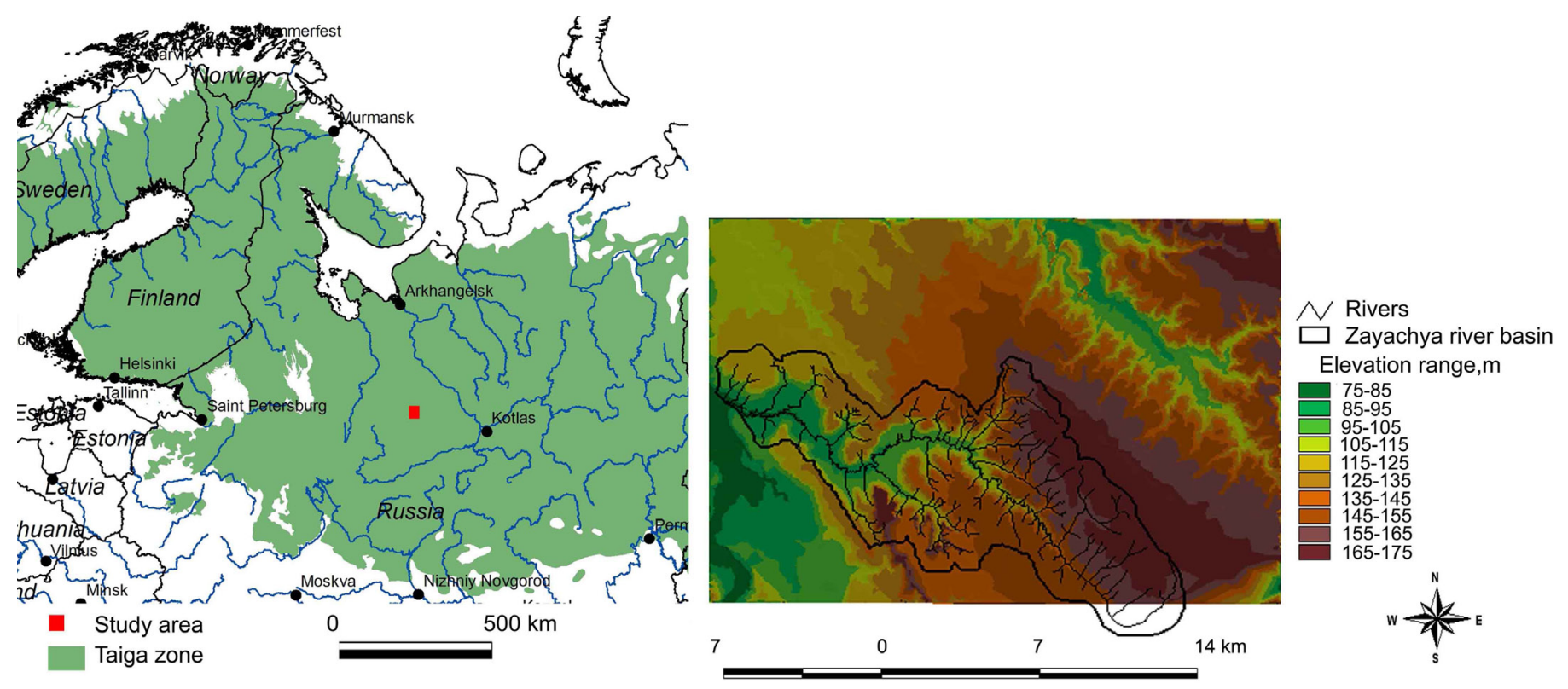

Figure 1: Location (left) and digital elevation model (right) of the study area. 
horizons (11 variables), Munsell color - hue, value, and chroma - measured over the interval $5 \mathrm{~cm}$ (30 variables), and texture measured over the interval 5 $\mathrm{cm}$ as a ranks of clay content (10 variables).

We used topographic map (1: 50,000) to compose digital elevation model (DEM) using triangulation technique. We deliberately focused on low-resolution $(400 \mathrm{~m})$ DEM to omit from examination fine details of relief (small rills, oxbows, debris slopes etc.) and to concentrate on mesoscale landforms (e.g. valley slopes, ravines, terraces, floodplains) and the related contrasts in soil and vegetation cover. Each sample plot was georeferenced to a DEM pixel which was used as a square operational territorial unit (OTU). ArcView 3.2a and Fracdim (Khoroshev \& Aleshchenko 2008) software were applied to calculate 4 morphometric features of relief characterizing intensity of lateral matter transfer: standard deviation of elevations (vertical dissection, VD below), total length of valleys (horizontal dissection, HD below), vertical curvature (VC), and horizontal curvature ( $\mathrm{HC})$. These variables were calculated in a moving window with linear dimension ranging from 1200 to $6000 \mathrm{~m}$ with step size $800 \mathrm{~m}$, the results being centered on the focal OTU provided by field data.

\subsection{Multiscale analysis of landscape structure}

We elaborated the special procedure called "Multiscale Analysis of Landscape Structure" (MALS) which includes seven steps.

At step 1 reduction of dimensionality of field data was performed. Strong deviation of raw quantitative data from normal distribution required applying non-parametric techniques. Multidimensional scaling was chosen as a method with no restrictions for normality and non-linearity (Cox \& Cox 2001), more precisely its nonmetric version (NMDS below) (Legendre \& Legendre 1988). For each group of attributes, we calculated non-parametric Gamma correlations and converted correlation $(r)$ matrix to distance $(d)$ matrix by equation $d=1-r$. We applied multidimensional scaling to distance matrix to calculate the measure of sensitivity of each variable $\left(a_{1 i} \ldots a_{4 i}\right)$ to the axes (dimensions it terms of NMDS). To derive appropriate number of axes (NA) we plotted the stress value against numbers of dimensions and analyzed the scree plot obtained. Then we calculated the coordinates of the sample plots (i.e. OTU provided by field descriptions) on the axes of ecological factors from the system of equations:

$$
y_{i}^{j}=a_{1 i} x_{1}^{j}+a_{2 i} x_{2}^{j}+a_{3 i} x_{3}^{j}+a_{4 i} x_{4}^{j}
$$

where $y_{i}^{j}$ : - known value of the variable $i$ measured at the sample plot $j, a_{1 i} \ldots a_{4 i}-$ sensitivity coefficients for the variable $i$ in relation to the axes 1, 2, 3 or 4; $\mathrm{x}_{1}{ }^{j} \ldots \mathrm{x}_{4}{ }^{\mathrm{j}}$ - coordinate value for the sample plot $j$.

The axes were rationalized as the geocomponents properties, that is sensitivity of soils or phytocoenoses to ecological factors according to the requirements of horizons or species, respectively. The coordinates of the sample plots on NMDS axes $x_{1}{ }_{1} \ldots x_{4}{ }^{j}$ calculated from (1) are below referred to as $D_{r g}$, where $r$ - rank, g - geocomponent, e.g. herbs, trees, soil horizons etc.).

At step 2 the data base was composed and processed in order to distinguish the spatial and non-spatial effects in interactions between the geocomponents. The data base included the coordinates of each sample plot on the axes $D_{r g}$ of ecological factors (i.e. properties of soils or phytocoenoses) and morphometric relief features for the hypothetic higher-order geosystems with the abovementioned linear dimensions $(1200 \ldots 6000 \mathrm{~m})$. Normal distribution of the plots coordinates on the NMDS axes values allowed performing principal components analysis (PCA) (Davis 2002) to reduce dimensionality and distinguish the groups of properties with various contributions of the internal (focus-level) and external (higher-level) factors of variability. The appropriate number of principal components was determined from the plot of Eigenvalues vs. Number of principal component considering the sharpest decrease of Eigenvalue. The purpose was to derive two groups of the orthogonal "super-factors". To distinguish them, we analyzed factor loadings for each principal component. The first group of "superfactors" was expected to control the properties $D_{r g}$ that vary in concordance with the relief properties of one or several higher-order geosystems (i.e. $D_{\mathrm{rg}}$ and relief properties have factor loading far from zero and close to either maximum or minimum values). This would mean that the properties are sensitive to the external spatial influences generated at the higher level (i.e. inter-level interactions). The 
second group of "super-factors" was expected to control the properties $D_{r g}$ that vary in concordance with each other (soil-vegetation, sediments-soils relationships etc.) but independently of the higherorder geosystems which was indicated by close to zero factor loadings for relief properties. This would testify the result of the internal non-spatial relations and self-development at the focus scale level (i.e. intra-level interactions). Of course, each property to some extent can be sensitive to both groups of super-factors.

At step 3 for each property of soils and phytocoenoses we composed two response surface regression (RSR) models (Eq. 2.1, 2.2):

$\mathrm{D}_{\mathrm{rg}}=\mathrm{a}+\mathrm{b}_{1} \mathrm{x}_{1}+\mathrm{b}_{2} \mathrm{x}_{1}{ }^{2}+\mathrm{b}_{3} \mathrm{x}_{2}+\mathrm{b}_{4} \mathrm{x}_{2}{ }^{2}+\mathrm{b}_{5} \mathrm{x}_{1} \mathrm{x}_{2}+\ldots+\mathrm{b}_{\mathrm{m}} \mathrm{x}_{\mathrm{n}} \mathrm{x}_{\mathrm{k}} \pm \varepsilon$ $(2.1,2.2)$ where $D_{r g}$-coordinates of a sample plot on the NMDS axis, $x_{n, k}$-values of internal (Eq. 2.1) or external (Eq. 2.2) PCA "super-factors".

By comparing coefficient of determination $\left(r^{2}\right)$ and statistical significance ( $p$-value) of equations $(2.1,2.2)$ we separated contributions of external and internal factors and concluded whether it is necessary to consider relief of surrounding landscape in order to explain spatial variability of a property under consideration.

Step 4 is aimed at the determination of relevant scale level of a higher-order geosystem to explain variability of the topography-driven attributes. RSR was used to relate the NMDS coordinates to the morphometric features of relief in a square neighborhood of those pixels in which field description was performed.

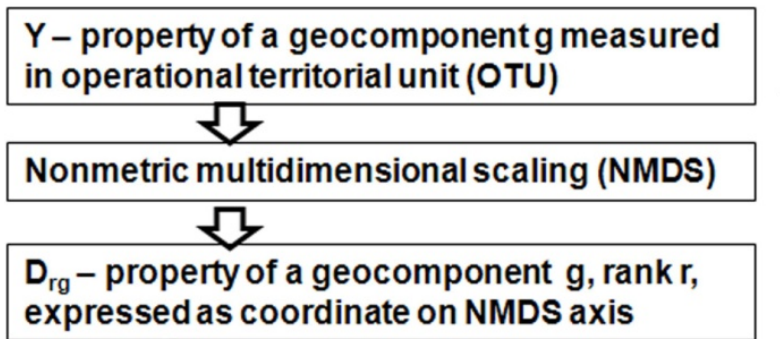

$\mathrm{X} 1_{1}, \mathrm{X} 1_{2}, \mathrm{X} 1_{3}, \mathrm{X} 1_{4}$

$\mathrm{X} 2_{1}, \mathrm{X} 2_{2}, \mathrm{X} 2_{3}, \mathrm{X} 2_{4}$

$\mathrm{X} 3_{1}, \mathrm{X} 3_{2}, \mathrm{X} 3_{3}, \mathrm{X} 3_{4}$

Morphometrical features $(1,2,3,4)$ of relief in a square neighborhood $1,2,3$ etc.

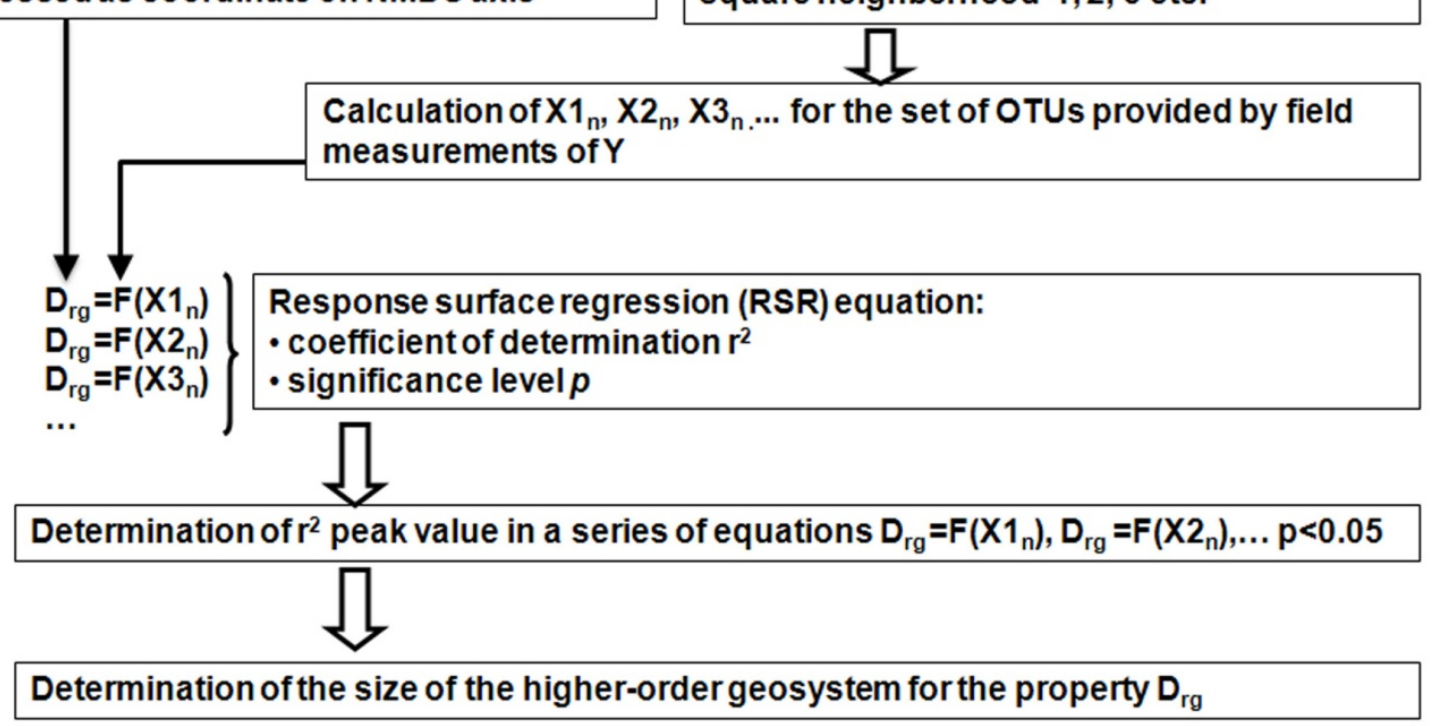

Figure 2: Procedure for determination of relevant size of the higher-order geosystems that control spatial variability of a geocomponent property. The value of property is measured in operational territorial unit (OTU) and expressed as coordinate on the axis of multidimensional scaling (NMDS) 
RSR equations were composed separately for each hypothetic size of a higher-order geosystem (namely, $3,5, \ldots, 15$ times as large as the linear dimension of OTU):

$D_{r g}=a+b_{1} X_{1}+b_{2} X_{1}^{2}+b_{3} X_{2}+b_{4} X_{2}^{2}+b_{5} X_{1} X_{2}+\ldots+b_{m} X_{n} X_{k} \pm \varepsilon$

where $D_{r g}$ - value of a property (coordinates of a sample plot on the NMDS axis), $X_{n}$ - morphometric features of relief in a higher-order geosystem (VD, HD, VC, and HC) (Fig. 2).

Comparison of equations composed for various sizes of a higher-order geosystem provides the opportunities as follows:

- to choose the equation with the highest $r 2$ and, hence, to determine "resonance scale level" of a higher-order geosystem that affects the OTU state $^{1}$;

- to clarify whether one or several scale levels of the higher-order geosystems are critical for the OTU state;

- to identify the set of topographic variables that serve as statistically significant predictors for the OTU state;

- to determine whether the topographic predictor correlates with the dependent property positively or negatively.

At step 5 we tested the hypothesis that the combined effect of several higher-order geosystems (step 3) contributes to spatial variability of OTU attributes more effectively than the individual effects of each higher-order geosystem (step 4). It was assumed that we inevitably lost some amount of information about relief at step 2 . In contrast, at step 4 we did not lose any information while composing equations separately for each hypothetical "resonance scale level". Suppose that equation for the combined effect of several higher-order geosystems (step 3 ) explains more variance of a property as compared to any of the equations explaining the individual influence of

1 Similar approach was applied by Cushman et al. (2009), Miguet et al. (2016) to explain the relationship between the biological response and landscape structure for each spatial extent and to find the scale at which the variable most strongly responds. some higher-order geosystem. This would testify that, despite the loss of information, the combined effect of several higher-order geosystems is more significant than the individual contribution of any higher-order geosystem. If this is not true, one can conclude that no emergent effect of a higher-order geosystems exists.

At step 6 the purpose was to create a series of cartographic models that would express both the interrelationships of geocomponents and the possible multiplicity of higher-order geosystems. We performed classification of pixels (OTUs) by a set of four abovementioned morphometric relief features in a "resonance" square environment determined at step 4. Multistructural organization of a landscape forces us to compose a series of maps, not a single one. Each of these maps follows the deterministic logic: "under the given combination of landforms in surroundings the unit has the soil-vegetation class X". A map in this case shows partial geosystems, or geocomplexes (e.g. water-sensitive, nutrientsensitive etc.), shaped by specific system-forming process with varying degree of manifestation across a landscape.

After that, the OTUs described in field were classified by those attributes of soils and vegetation that appeared to be sensitive to the same ecological factor. Separate classifications were performed for the water-sensitive and nutrient-sensitive attributes. Then, class membership was used in discriminant analysis as a grouping variable. Morphometric features of relief in several "resonance" square environments were taken as response variables. Statistically significant morphometric features were selected using Forward stepwise method $(F=1)$ in Statistica 7.0 software. By this, we predicted the soil-vegetation class with the highest membership probability for each OTU. At this step we followed the probabilistic logic: "under the given influence of the higher-order geosystems the soil-vegetation class X has the highest probability of occurrence".

Step 7 included quantitative evaluation of uncertainty in predicting soil-vegetation classes, since we can easily suppose landforms combinations that permit occurrence of several soil-vegetation classes with similar probabilities. To calculate uncertainty of class prediction we applied the Shannon formula: 
$\mathrm{H}=-\Sigma \mathrm{p}_{i}{ }^{*} \log \left(p_{i}\right)$

where $\mathrm{H}$ - uncertainty of class membership, $p_{i}-$ probability that class $i$ will occur under current combination of landforms in significant neighborhoods.

\section{Results}

\subsection{Driving ecological factors}

For most groups of variables NMDS showed smooth decrease of stress values which level off to the right of number of dimensions " 4 ". For example, for the tree layer (10 variables) under 3, 4, 5 and 6 dimensions D-star raw stress accounted for $0.7142420 .2323432,0.0575684$ and 0.0000051 , respectively. Therefore, for each group of variables, we derived four NMDS axes $(N A=4)$ to ensure the same number of degrees of freedom in RSR equations. Similarly, four morphometric features of relief were calculated for each size of square neighborhood. RSR modeling indicated that $60-80 \%$ of variance of most raw field data was explained by the coordinates on axes nos. $1 \ldots 4$. The $1^{\text {st }}$ and $2^{d}$ axes for most geocomponents were interpreted as the sensitivity to either nutrients or water supply. For example, if the thickness of humus horizon was scoring low on the axis and that of podzolic horizon scoring high, the axis was interpreted as a degree of nutrients supply depending strongly on soil-forming sediments.

We found evidence that the nutrients supply has the highest significance for trees, shrubs, and herbs, while water supply - for low shrubs, mosses, thickness of soil horizons, and soil colors. Spearman correlations indicated significant relationships between the $D_{r g}$ values for various geocomponents. For example, the values of the $1^{\text {st }}$ axis for trees (Pinus sylvestris vs. Picea abies) correlate negatively with the $2^{\mathrm{d}}$ axis for soil horizons (humus vs. podzolic horizon). This corresponds to response of trees to a gradient from nutrient-poor sandy soils to nutrientrich loamy ones.

\subsection{Number and size of higher-order geosystems}

VD, HD, VC, and HC as the predictors in Eq. (3) were repeatedly computed at a range of spatial extents around each location using a moving window with linear dimensions 1200, 2000, 2800, 3600, 4400, 5200 , and $6000 \mathrm{~m}$. Coefficients of determinations $\mathrm{r}^{2}$ in RSR models relating the NMDS axes to relief see in Fig. 3. Evidently, most properties of vegetation and soils are scale-sensitive and exhibit the best response to the relief of geosystems with linear dimension either $1200 \mathrm{~m}$ or $2000 \mathrm{~m}$. Higher-order geosystems with linear dimension $1200 \mathrm{~m}$ provide

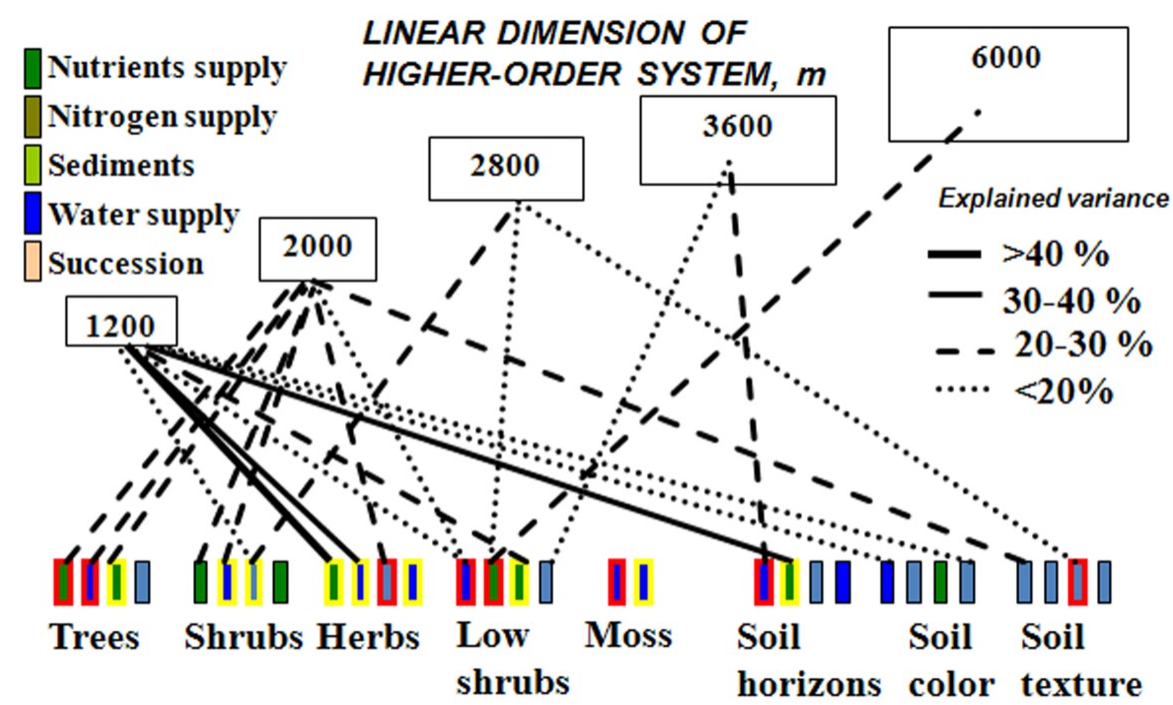

Figure 3: External effects of linkages between soil-vegetation properties $D_{r g}$ and morphometric features of the higherorder geosystems relief. Percentage of variance explained by the Response regression surface equation (3). Red outline: internal non-spatial factors are stronger than external spatial ones. Yellow outline: external spatial factors are more significant. 
A

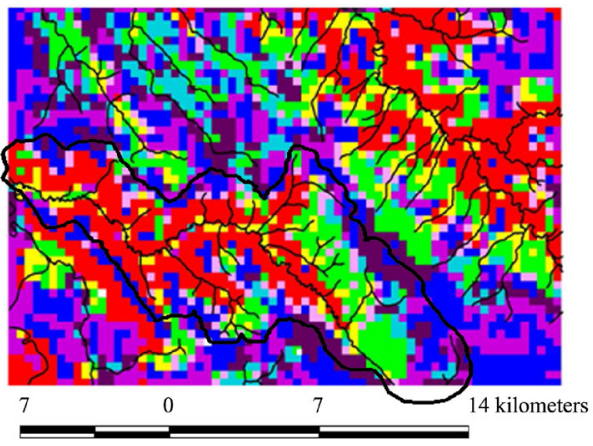

B

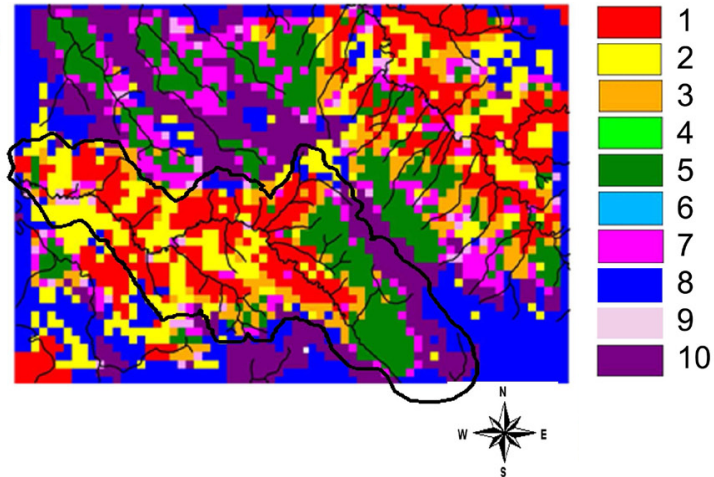

Figure 4: Maps of partial geosystems based on the deterministic model: "Properties of geosystems $\left(D_{\mathrm{rg}}\right)$ are strictly determined by landforms combination in the square neighborhood". Colors correspond to the types of units embedded into the higher-order geosystems with linear dimensions: A - $1200 \mathrm{~m}$ (properties of herb, low shrub, shrub layers, soil horizons), B - $2000 \mathrm{~m}$ (properties of tree and shrub layers). Bold black curve - boundary of the Zayachya river basin

Relief properties: 1 - rugged terrains with dense erosion network; 2 - flat terraces and marginal parts of narrow flat interfluves; 3 (B) - slightly concave catchment areas with flat slopes; 4 (A) and 5 (B) green - gentle slightly dissected slopes; 6 (A) - Slightly convex narrow interfluves with gentle slopes; 7 (B) - flat interfluves surrounded by the upper reaches of the valleys; 8 - wide flat poorly drained interfluves; 9 (A) - flat drained interfluves; 10 - narrow flat poorly drained interfluves

constraints for the properties of herbs, shrubs, low shrubs, thickness and color of soil horizons (Fig. 4, A). Tree and shrub layers and, to some extent, soil texture (i.e., more precisely, genesis of soil-forming sediments) demonstrated the most obvious response to the properties of the larger " $2000 \mathrm{~m}$ " geosystems which show explicitly step-like organization of relief (Fig. 4, B).

\subsection{Contributions of internal and external effects: relief-sensitive vs. relief-insensitive properties}

Eight mutually independent "super-factors" explained $54 \%$ of variance for the whole set of the NMDS axes. Among them the $1^{\text {st }}, 2^{\mathrm{d}}, 6^{\text {th }}$ and $7^{\text {th }}$ superfactors (referred to as "external" below) turned out to be highly sensitive to the relief of the higher-order geosystems. For example, super-factor 1 reflects variability of VD and HD in distant environment (2800$6000 \mathrm{~m}$ ) and indicates the high-order neotectonic blocks, while super-factor 2 controls curvatures in the closest environment (1200-2800 m). The same super-factors describe variability of some properties of plant and soil cover, e.g. the $1^{\text {st }}$ and the $2^{\mathrm{d}}$ axes for the herb layer being indicative of nutrient and water supply, respectively.

In contrast, four other super-factors (nos. 3, 4, 5, 8) were insensitive to the relief of surroundings. They have high factor loadings for the $1^{\text {st }}$ axis for trees, the $2^{\mathrm{d}}-$ for low shrubs, the $1^{\text {st }}$ axis for mosses, and the $3^{d}$ axis for herbs. From this fact we conclude that the internal interactions between these attributes of vegetation layers in situ have higher significance than the broad-scale processes. These superfactors are referred to as "internal" below. Several properties demonstrated sensitivity both to external and internal super-factors.

For each axis we compared proportion of variance explained by four relief-sensitive super-factors vs. four relief-insensitive ones (Table 1). For example, percentage of variance of the $2^{\mathrm{d}}$ axis for trees (sensitivity to water supply) explained by the reliefsensitive external super-factors accounted for $31 \%$, while relief-insensitive super-factors independently explained $40 \%$. For most axes super-factors explain much less than $100 \%$ of variance, $86 \%$ for the $1^{\text {st }}$ axis for herbs being the maximum.

Remember that at previous steps we determined individual contribution of each level of the higherorder geosystems. Percentage of variance of the $1^{\text {st }}$ axis for herbs (sensitivity to nutrient supply) explained by properties of geosystems with linear dimensions $1200,2000,2800,3600$, and 6000 m accounted for $40,34,28,25$, and $26 \%$ respectively. However, the combined emergent effect of the external superfactors accounted for $59 \%$ (Table 1). This greater figure integrates not only the influence of broad-scale 
processes (e.g. relief-dependent water migration) but also the non-linear relationships between the relief-dependent properties of soil and plant cover. In contrast, the single-level dependence holds true for several axes responsible for variability of texture and soil colors (the $1^{\text {st }}$ and $4^{\text {th }}$ axes).

Table 1: Contributions of the external and internal effects on spatial variability of geocomponents properties $\mathrm{Drg}$ (where $r$ - rank, g - geocomponent) expressed by axes of multidimensional scaling (NMDS). Bold italic letters significant equations

\begin{tabular}{|c|c|c|c|}
\hline \multirow{2}{*}{$\begin{array}{c}\text { Properties } \\
D_{r g}\end{array}$} & \multicolumn{3}{|c|}{ Percentage of variance explained by: } \\
\hline & $\begin{array}{c}4 \text { relief-sensitive } \\
\text { (external) } \\
\text { superfactors }\end{array}$ & $\begin{array}{c}4 \text { relief-insensitive } \\
\text { (internal) } \\
\text { superfactors }\end{array}$ & $\begin{array}{c}\text { Totally } 8 \text { external } \\
\text { and internal } \\
\text { superfactors }\end{array}$ \\
\hline$D_{1 \text { herbs }}$ & 59 & 27 & 86 \\
\hline$D_{2 \text { herbs }}$ & 45 & 20 & 65 \\
\hline$D_{3 \text { herbs }}$ & 18 & 44 & 62 \\
\hline$D_{4 h e r b s}$ & 24 & 15 & 39 \\
\hline $\mathrm{D}_{1 \text { trees }}$ & 16 & 34 & 52 \\
\hline$D_{2 \text { trees }}$ & 31 & 40 & 71 \\
\hline$D_{3 \text { trees }}$ & 39 & 20 & 59 \\
\hline$D_{4 \text { trees }}$ & 13 & 9 & 22 \\
\hline$D_{1 \text { low shrubs }}$ & 25 & 39 & 64 \\
\hline$D_{\text {2low shrubs }}$ & 11 & 37 & 48 \\
\hline$D_{3 \text { low shrubs }}$ & 32 & 38 & 70 \\
\hline$D_{\text {4low shrubs }}$ & 12 & 17 & 29 \\
\hline$D_{1 \text { shrubs }}$ & 39 & 37 & 76 \\
\hline$D_{2 \text { shrubs }}$ & 29 & 18 & 47 \\
\hline$D_{3 \text { shrubs }}$ & 33 & 15 & 48 \\
\hline$D_{4 \text { shrubs }}$ & 12 & 28 & 40 \\
\hline$D_{1 \text { mosses }}$ & 7 & 24 & 31 \\
\hline$D_{2 \text { mosses }}$ & 27 & 21 & 48 \\
\hline$D_{1 \text { soil color }}$ & 14 & 21 & 35 \\
\hline$D_{2 \text { soil color }}$ & 8 & 19 & 27 \\
\hline$D_{3 \text { soil color }}$ & 22 & 9 & 31 \\
\hline$D_{4 \text { soil color }}$ & 19 & 13 & 32 \\
\hline$D_{5 \text { soil color }}$ & 11 & 10 & 21 \\
\hline$D_{6 \text { soil color }}$ & 20 & 15 & 35 \\
\hline$D_{1 \text { soil horizons }}$ & 17 & 39 & 56 \\
\hline$D_{2 \text { soil horizons }}$ & 39 & 26 & 65 \\
\hline$D_{3 \text { soil horizons }}$ & 10 & 9 & 19 \\
\hline$D_{4 \text { soil horizons }}$ & 12 & 18 & 30 \\
\hline $\mathrm{D}_{1 \text { soil texture }}$ & 15 & 13 & 28 \\
\hline$D_{2 \text { soil texture }}$ & 3 & 15 & 18 \\
\hline$D_{3 \text { soil texture }}$ & 12 & 21 & 33 \\
\hline $\mathrm{D}_{4 \text { soil texture }}$ & 5 & 11 & 16 \\
\hline
\end{tabular}

The internal super-factors contributed to the spatial variability of the properties linked with feedbacks. For example, the $3^{\mathrm{d}}$ axis for herbs (Majanthemum bifolium, Oxalis acetosella, Linnaea borealis vs. Heracleum sibiricum, Carex canescens, Equisetum sylvaticum) is slightly sensitive to relief of the "2000 $m$ " geosystem but experience no any emergent effect of higher-order geosystems. At the same time emergent effect of the four internal super-factors is large. The property has poor correlation with abiotic environment but strong - with the forest stand age, canopy cover, canopy height, and tree diameter. Obviously, the abundance of this group of herbs is related to self-regulation in phytocoenosis during the recovery succession.

\subsection{Probabilistic cartographic models of partial geosystems}

To compose the series of maps of partial watersensitive (WS) and nutrient-sensitive (NS) geosystems we applied the probabilistic approach. We performed classification of units based on watersensitive properties that were linked by strong Spearman rank correlation. 8 soil-vegetation WSclasses were identified. Then we used discriminant analysis to test the hypothesis that each WS-class occurs under the specific combination of relief attributes imposed by the higher-order geosystems as well as by slope gradient in the OTU. Forward stepwise method $(F=1)$ was used to identify the significant relief morphometric features that were able to distinguish 8 soil-vegetation WS-classes (Table 2). Only $32 \%$ of the units provided with field descriptions were correctly classified (Wilks' Lambda $=0.41441$ ). This is not a surprise since most water-sensitive properties depend much more on the internal factors than on the external ones. The map in Fig. 5 shows the location of 8 soil-vegetation WS-classes that were predicted based on the highest probability of occurrence under the given relief conditions. However, it shows location more or less perfectly only for well-discriminated WS-classes $2,6,7,8$ which can occur under the specific relief conditions that are not inherent for any other class.

For example, WS-class 2 (Fig. 5) is typical for the areas with the highest VD due to the outcroppings of Permian marlstones close to water streams. In the well-drained habitats secondary aspen forests dominate, soils have thick humus and very thin podzolic horizons. Absence of Vaccinium myrtillus (commonly, typical for the taiga) indicates low level of groundwater. Hence, water regime resembles the southern taiga rather that the middle taiga. 
Table 2: Forward stepwise selection of the relief morphometric features significant to distinguish 8 classes of units identified by either water-sensitive or nutrient-sensitive properties

\begin{tabular}{|c|c|c|c|c|c|c|}
\hline \multirow{2}{*}{$\begin{array}{l}\text { Relief morphometric features } \\
\text { and linear dimension of the } \\
\text { higher-order geosystem }\end{array}$} & \multicolumn{3}{|c|}{$\begin{array}{l}\text { The model for the water- } \\
\text { sensitive properties }\end{array}$} & \multicolumn{3}{|c|}{$\begin{array}{l}\text { The model for the nutrient- } \\
\text { sensitive properties }\end{array}$} \\
\hline & $\begin{array}{l}\text { Wilks' } \\
\text { Lambda }\end{array}$ & $\begin{array}{c}\mathrm{F}- \\
\text { remove }\end{array}$ & $\begin{array}{c}\mathrm{p}- \\
\text { level }\end{array}$ & $\begin{array}{l}\text { Wilks' } \\
\text { Lambda }\end{array}$ & $\begin{array}{l}\text { F- } \\
\text { remove }\end{array}$ & $\begin{array}{c}\mathrm{p}- \\
\text { level }\end{array}$ \\
\hline Vertical dissection, $1200 \mathrm{~m}$ & 0.44 & 1.24 & 0.28 & 0.29 & 3.48 & 0.001 \\
\hline Slope & 0.44 & 1.25 & 0.28 & 0.26 & 1.13 & 0.35 \\
\hline Vertical dissection, $6000 \mathrm{~m}$ & 0.46 & 2.63 & 0.01 & 0.27 & 1.94 & 0.06 \\
\hline Vertical curvature, $1200 \mathrm{~m}$ & 0.44 & 1.45 & 0.19 & 0.27 & 1.85 & 0.08 \\
\hline Horizontal curvature, $2000 \mathrm{~m}$ & 0.46 & 2.30 & 0.03 & 0.27 & 1.65 & 0.12 \\
\hline Vertical dissection, $3600 \mathrm{~m}$ & 0.46 & 2.47 & 0.02 & 0.28 & 2.86 & 0.007 \\
\hline Vertical dissection, $2800 \mathrm{~m}$ & 0.45 & 2.11 & 0.04 & - & - & - \\
\hline Vertical dissection, $2000 \mathrm{~m}$ & 0.43 & 1.14 & 0.34 & - & - & - \\
\hline Vertical curvature, $2800 \mathrm{~m}$ & - & - & - & 0.26 & 1.34 & 0.23 \\
\hline Horizontal dissection, $2000 \mathrm{~m}$ & - & - & - & 0.27 & 2.04 & 0.05 \\
\hline Vertical curvature, $2000 \mathrm{~m}$ & - & - & - & 0.26 & 1.25 & 0.27 \\
\hline Horizontal dissection, $1200 \mathrm{~m}$ & - & - & - & 0.26 & 1.54 & 0.15 \\
\hline Horizontal curvature, $1200 \mathrm{~m}$ & - & - & - & 0.26 & 1.33 & 0.24 \\
\hline Horizontal dissection, $6000 \mathrm{~m}$ & - & - & - & 0.27 & 1.62 & 0.13 \\
\hline Horizontal dissection, $3600 \mathrm{~m}$ & - & - & - & 0.27 & 1.53 & 0.16 \\
\hline Horizontal curvature, $3600 \mathrm{~m}$ & - & - & - & 0.26 & 1.03 & 0.41 \\
\hline
\end{tabular}

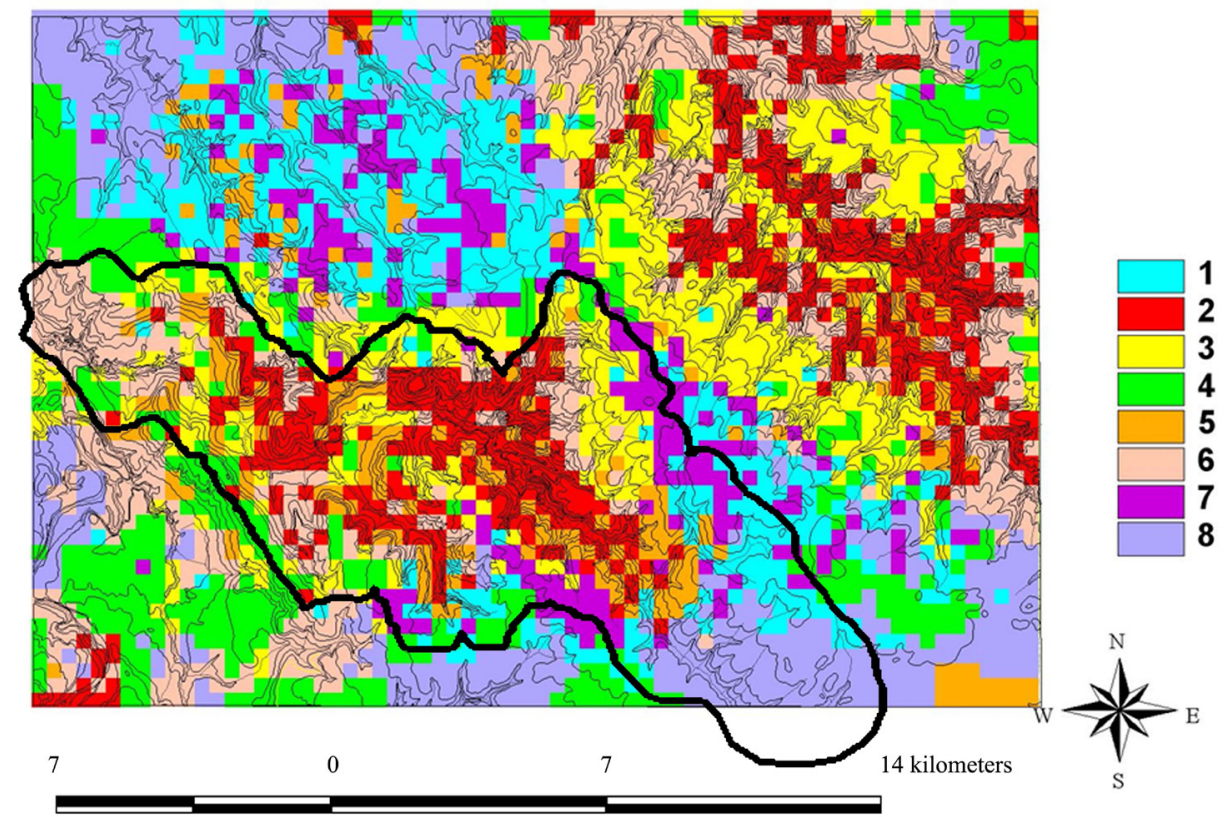

Figure 5: Multiscale cartographic model of the most probable soil-vegetation WS-classes based on water-sensitive properties. Bold black curve - boundary of the Zayachya river basin

Main features of soil-vegetation WS-classes: 1 - dominance of spruce, Vaccinium myrtillus, podzolic horizon in soils with long-term gleyization. 2 - dominance of aspen and alder, absence of Vaccinium myrtillus, well-drained soils with humus horizon. 3 - high abundance of pine and Pleurozium schreberii on drained sandy soils with short-term gleyization in spring with legacy of ploughing. 4 - high abundance of pine, Vaccinium myrtillus, Vaccinium vitis-idaea, on drained sandy soils with temporary gleyization and thick podzolic horizon. 5 - high abundance of spruce, Pleurozium schreberii on well-drained soils without gleyization. 6 - high abundance of alder and herbs, absence of mosses on well-drained soils with legacy of ploughing. 7-high abundance of spruce, pine, Sphagnum mosses on poorly-drained soils with peat and gley horizons. 8- dominance of pine, Vaccinium myrtillus, Vaccinium vitis-idaea, and Sphagnum mosses on poorlydrained soils with peat, podzolic and gley horizons. 

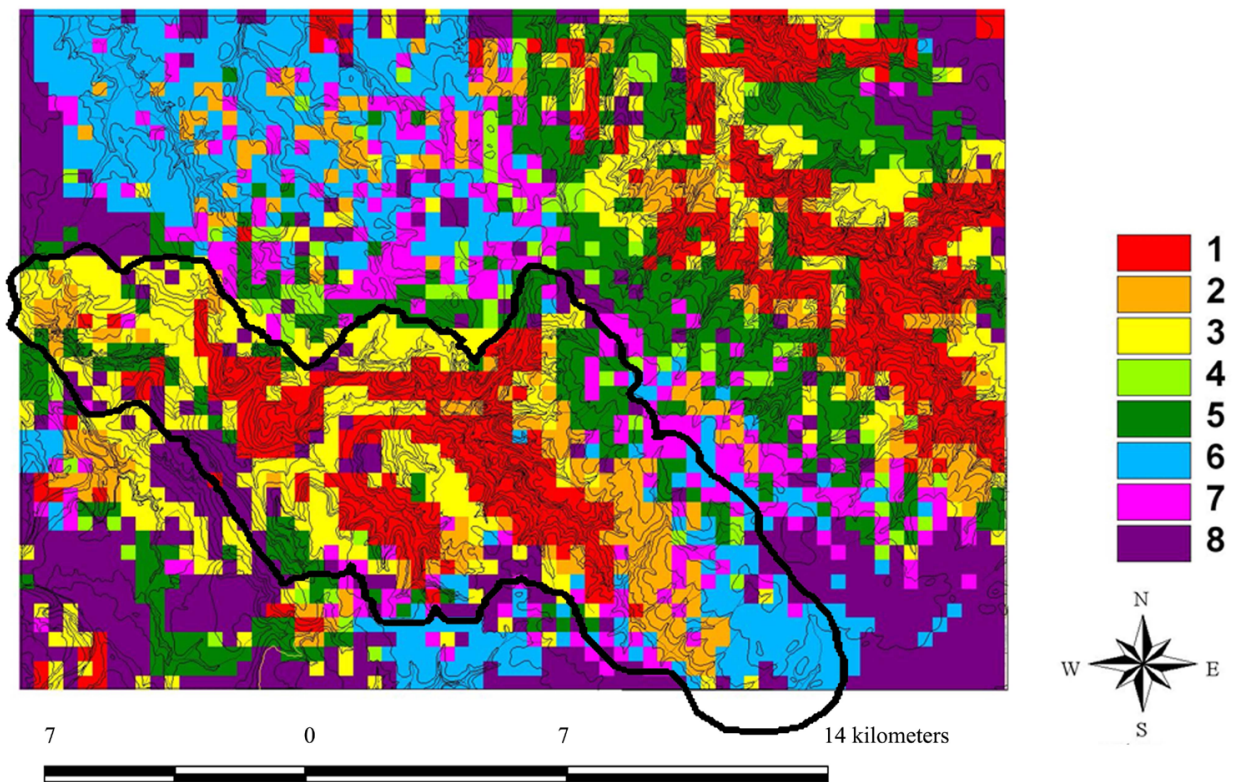

Figure 6: Multiscale cartographic model of the most probable soil-vegetation NS-classes based on nutrient-sensitive properties. Classes $1 . . .8$ - see in text. Bold black curve - boundary of the Zayachya river basin

Main features of soil-vegetation NS-classes: 1 - dominance of alder, aspen, and megatrophic herb species or cultivated areas on humus-rich weakly alkaline soils. 2 - high abundance of mesotrophic and megatrophic herb and shrub species on nutrient-rich weakly acid soils. 3 - dominance of pine, Vaccinium vitis-idaea, and boreal herbs on nutrient-poor strongly acid soils. 4 - elevated abundance of spruce, pine, boreal mesophytes, and hygrophytes on nutrient-poor weakly acid soils. 5 - high abundance of pine, boreal mesophytes and hygrophytes on weakly acid soils with medium nutrients supply. 6 - dominance of spruce, pine, and typical boreal species on nutrient-poor acid soils. 7 - elevated abundance of aspen, Vaccinium myrtillus, and boreal herbs on weakly acid soils with medium nutrients supply. 8 - high abundance of pine and boreal species or hygrophytes on strongly acid nutrient-poor soils.

Analogously, we identified 8 soil-vegetation NSclasses based on the set of the nutrient-sensitive attributes and performed discriminant analysis in relation to the relief attributes. Percentage of correct classification accounted for $43 \%$ (Wilks' Lambda $=0.25127$ ). Since most attributes are governed by external factors, the quality of discrimination was higher than that for the watersensitive attributes. The most probable NS-class for each pixel is shown in Fig. 6. NS-classes 1, 3, 6,7 exhibited the highest percentage of correct discrimination.

For example, NS-class 1 (Fig. 6) to a large extent overlaps with the WS-class 2 (Fig. 5) for the watersensitive properties. However, its areal is less perforated by the other NS-classes. The highest level of nutrient supply determines high abundance of Populus tremula and Alnus incana in tree layer as well as herbs and shrubs that are more characteristic for the broad-leaved forests (e.g. Pulmonaria officinalis, Paris quadrifolia) or for floodplains and fens (Filipendula ulmaria, Aconitum septentrionale, Ribes rubrum, Lonycera xylosteum). Soils have the thickest humus horizons. Since nutrient supply in the study area is closely connected to the emergence of groundwater, one can see certain overlaps between WS- and NS-classes.

The maps of uncertainty (Fig. 7) show in which locations a set of external and internal factors allows occurrence of several possible soil-vegetation WSand NS-classes. Less uncertainty was detected at the map of nutrient-induced patterns (Fig. 7, B), the lowest uncertainty occurring in the most dissected and the least dissected areas. These locations correspond, respectively to the maximum and minimum possible influence of marlstone. 


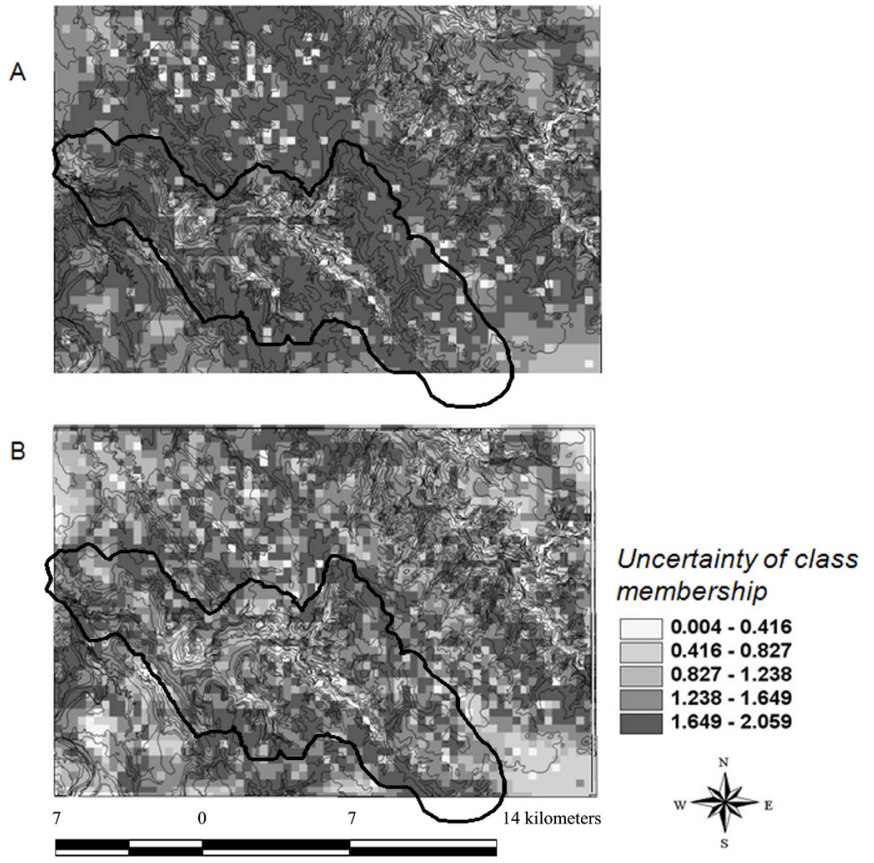

Figure 7: Uncertainty of class membership for the multiscale cartographic models of soil-vegetation classes based on water-sensitive $(A)$ and nutrient-sensitive (B) properties. Bold black curve - boundary of the Zayachya river basin

\section{Discussion}

Advance in the formalized techniques of landforms delineation provides the opportunities to predict habitats, forest types, soil patterns etc. based on the models of their various relationships with abiotic template. Our results at step 2 of MALS showed the efficiency of distinguishing two groups of landscape attributes. The first group is governed by the internal interactions between the geocomponents within a geosystem; the second one - by broad-scale processes in the higher-order geosystems. In order to compose the topography-based landscape maps (step 6) correctly, we identified the topographysensitive properties and determined the relevant scale levels of their manifestation (step 4). In our research hierarchical levels were revealed by evaluating linkages between the properties of the focus unit and spatial emergent properties of embracing higher-order geosystem. Each attribute of soil and vegetation can receive significant signal from one or several rank-orders of geosystems simultaneously.
The list of attributes sensitive to the " $1200 \mathrm{~m}$ " geosystems established at step 4 involves the axes with the highest explained variance (i.e. No. 1) for herbs, low shrubs, soils colors which are indicative of either water or nutrient supply. The higher terrain ruggedness results in decrease of groundwater level and less occurrence of temporary perched soil water. Herbs and low shrubs respond to water supply by substitution of communities with Orchis maculata, Luzula pilosa, Linnaea borealis by those with Asarum europaeum, Gymnocarpium dryopteris, Vaccinium vitis-idaea etc. Trees and mosses ignore processes inherent for this level. HD is close to zero in the central sectors of the interfluves, but high - in the belt of runoff formation in the upper sectors of gentle slopes. In the upper reaches with low VD and curvatures marlstones are hidden below the morainic and limnoglacial sediments, the soils being less base-saturated. Deep dissection favors frequent emergence of carbonate-rich groundwater and development of wet nutrient-rich habitats with dominance of Filipendula ulmaria, Aconitum septentrionale, Aegopodium podagraria, Trollius europaeus. Thus, the " $1200 \mathrm{~m}$ " geosystems delimited at step 6 correspond to patterns generated by erosion which favored drainage and increased contrast between the nutrient-poor and nutrient-rich habitats. Step-like organization of the "2000 m" geosystems pattern is obviously induced by southwestward inclination of Permian strata transformed by joints. The lower blocks in the southwestern sector were undergone to the wellmanifested influence of the dammed lakes during Würm glaciation and later - by fluvioglacial and alluvial accumulation of sand. The poorer nutrient supply is indicated by dominance of pine over spruce, high occurrence of Juniperus communis and better development of podzolic process without gleyization.

Our findings showed evidence that similar relief conditions and corresponding water- and nutrientinduced patterns allow multiplicity of combinations of soil and vegetation properties. Percentage of unexplained variance in the range of $20-40 \%$ for most axes (step 3), most likely, indicates that many processes are operating at the other scales, e.g. matter redistribution among micro-landforms. 
Our previous investigation in the same study area for the water-sensitive properties of plant cover showed that at least $30 \%$ of variance unexplained by coarse-scale model (DEM resolution $400 \mathrm{~m}$ ) can be explained by regression model based on calculations from the more detailed DEM (30 m) (Khoroshev et al. 2013).

The nutrient-induced patterns are more heterogeneous in the interior interfluve areas (Fig. 6) than the water-induced ones (Fig. 5). The latter form a series of belts from the water divides towards valleys. In the deeply dissected sectors, vice versa, nutrient-induced patterns are less diverse. It follows, that neither of two factors can be assigned the higher importance for landscape mapping. Multilevel cartographic models are less uncertain and more effective for the nutrient-sensitive properties than one-level ones (step 7). We identified three principal ways of subordination for the properties of soil and vegetation cover (step 5). First, a property can undergo priority influence of the other geocomponents independently on external factors. Second, a property can be influenced by ecological processes of a single higher-order geosystem that impose strict constraints on the possible range of values. Third, a property can be influenced by an emergent effect of several higher-order geosystems, i.e. by a set of broad-scale processes.

Our research confirmed the hypothesis that the combined effect of several higher-order geosystems provides emergent effect for the low-order landscape unit. The proportion of oligotrophic and megatrophic herb species is governed, to some extent, on the largest higher-order geosystems (3600-6000 m) which were shaped by different rates of Quaternary cover removal depending on rate of neotectonic uplift and resulting in soil enrichment by base cations from underlying marlstones. The lower-level geosystems (1200-2000 m) contributed by means of the present-day migration of nutrients with surface and subsurface waters along the slopes and thalwegs. This kind of results follows the idea that cross-scale interactions can generate emergent behavior that cannot be predicted based on observations at single or multiple independent scales and the interactions may produce nonlinear dynamics with thresholds (Peters et al. 2004) which is one of the most important attributes of the complex adaptive systems (Messier \& Puettmann, 2011).

The information translated from the higher-order geosystems is manifested mainly in the drainage conditions that depend on landforms pattern in certain neighborhood and control soil and vegetation properties. Most soil and vegetation properties are governed by not a single scale level but by a simultaneous action of a variety of processes at different spatial and temporal scales, number of which ranges from 2 to 5 . Our multiscale cartographic landscape model with the chosen OTU size was more relevant to describe nutrient redistribution. To detect water redistribution in details the chosen OTU size is too coarse. Most likely, it means that present-day redistribution follows to lesser extent the geological patterns but to a much greater extent - fine-scale flows among micro-landforms. Probabilistic landscape mapping (step 7) showed the areas with perfect adaptation of soils and vegetation to abiotic environment as well as areas with high possibility of several stable states. This way of mapping provides the promising opportunity to flatten the contradiction between the concepts of discrete and continual organization of nature.

\section{Conclusions}

The MALS procedure showed that in the investigated middle-taiga landscape herbs, low shrubs, and morphologic soil properties are controlled mainly by the geosystems with approximate linear size 1200 $\mathrm{m}$. Trees, shrubs, and to some extent sediments are subject to influence of more broad-scale phenomena in larger geosystems with linear size $2000 \mathrm{~m}$. Though for most properties one of scale levels contributes more than the others, from 2 to 5 levels of higherorder geosystems should be considered in order to obtain proper explanation of spatial heterogeneity. This information provides rationales to objectively delimit landscape units following the criterion of both geomorphologic and soil-vegetation homogeneity. 
From the concept of scale multiplicity, it follows that uniform rules of establishing boundaries for the whole set of properties hardly exist. We do not reveal relief hierarchical levels based on DEM beforehand as it is commonly performed in most studies. Instead, we tested a series of hypotheses about possible hierarchical levels of landscape organization using the criterion of statistically significant linkages between soil/vegetation property and relief of a higherorder geosystem. If a researcher finds evidence that the property is controlled by relief-dependent processes it is reasonable to turn to the advanced steps or research focusing on modeling gravityinduced matter and energy flows. If it is not the case the researcher should focus either on modeling dependence on succession stage or on geology. If one misses the stage of separation of factors contribution he/she faces the risk to mix up effects of independent factors. The proposed methodology is believed to be scale-invariant. It could be applied to any size of OTU and any neighborhood size.

\section{Acknowledgements}

The study was supported by Russian Foundation for Basic Research (RFBR projects 17-05-00447, 14-0500170). Contribution of G.M. Aleshchenkot, A.A. Prozorov, K.A. Merekalova, I.P. Kotlov to field research and processing data is greatly acknowledged. The author is grateful to G. Malanson, F. Papadimitriou, B. Pedroli, and anonymous reviewers for their fruitful comments on the earliest version of the manuscript.

\section{References}

Angelstam, P.; Grodzynskyi, M.; Andersson, K.; Axelsson, R.; Elbakidze, M.; Khoroshev, A.; Kruhlov, I. \& Naumov, V. 2013. Measurement, collaborative learning and research for sustainable use of ecosystem services: landscape concepts and Europe as laboratory. AMBIO 42, 129-145. DOI:10.1007/s13280-012-0368-0
Armand, A.D. \& Targul'yan, V.O. 1976. Some fundamental limitations on experimentation and model-building in geography. Soviet Geography 17, 197-206.

Avessalomova, I.A.; Khoroshev, A.V. \& Savenko, A.V. 2016. Barrier function of floodplain and riparian landscapes in river runoff formation. In: Pokrovsky, O.S. (ed.): Riparian zones. Characteristics, management practices, and ecological impacts. Nova Science Publishers; New York.

Bastian, O.; Grunewald, K. \& Khoroshev, A.V. 2015. The significance of geosystem and landscape concepts for the assessment of ecosystem services: exemplified on a case study in Russia. Landscape Ecology 30, 1145-1164. DOI: 10.1007/ s10980-015-0200-x

Berg, L.S. 1915. The objectives and tasks of geography. Proceedings of the Imperial Russian Geographical Society 51(9), 463-475 (In Russian). Also in: Wiens, J.A.; Moss, M.; Turner, M.G. \& Mladenoff, D.J. (eds.) 2006. Foundation Papers in Landscape Ecology. Columbia University Press; New York.

Bolstad, P.V.; Swank, W. \& Vose, J. 1998. Predicting Southern Appalachian overstory vegetation with digital terrain data. Landscape Ecology 13, 271283. DOI: $10.1023 / A: 1008060508762$

Borcard, D. \& Legendre, P. 2002. All-scale spatial analysis of ecological data by means of principal coordinates of neighbour matrices. Ecological Modelling 153, 51-68.

Burnett, C. \& Blaschke, T. 2003. A multi-scale segmentation/object relationship modeling methodology for landscape analysis. Ecological Modelling 168, 233-249. DOI: 10.1016/S03043800(01)00501-4

Carlile, D.W.; Skalski, J.R.; Batker, J.E.; Thomas, J.M. \& Cullinan, V.I. 1989. Determination of ecological scale. Landscape Ecology 2, 203-213. 
Chang, C-R.; Lee, P.F.; Bai, M-L. \& Lin, T.T. 2006. Identifying the scale thresholds for field-data extrapolation via spatial analysis of landscape gradients. Ecosystems 9, 200-214. DOI: 10.1007/ s10021-005-0095-5

Couteron, P.; Barbier, N. \& Gautier, D. 2006. Textural ordination based on Fourier spectral decomposition: a method to analyze and compare landscape patterns. Landscape Ecology 21, 555567. DOI: 10.1007/s10980-005-2166-6

Cox, T.F. \& Cox, M.A.A. 2001. Multidimensional Scaling. Chapman and Hall; London.

Cross, A. \& Perakis, S.S. 2011. Complementary models of tree species-soil relationships in oldgrowth temperate forests. Ecosystems 14, 248260. DOI: 10.1007 /si 002 1-010- 9407- 5

Cushman, S.A.; Littell, J. \& McGarigal, K. 2010. The problem of ecological scaling in spatially complex, nonequilibrium ecological systems. In: Huettmann, F. \& Cushman, S.A. (eds.): Spatial Complexity, Informatics, and Wildlife Conservation. Springer; Tokyo, Berlin, Heidelberg, New York. DOI: 10.1007/978-4-431-87771-4_3

Cushman, S.A. 2016. Multi-scale habitat selection modeling: a review and outlook. Landscape Ecology 31, 1161-1175. DOI: 10.1007/s10980016-0374-x

Cushman, S.A. \& McGarigal, K. 2002. Hierarchical, multiscale decomposition of species-environment relationships. Landscape Ecology 17, 637-646. DOI: 10.1023/A:1021571603605

Davis, J.C. 2002. Statistics and data analysis in geology. Wiley; New York.

Delcourt, H.R.; Delcourt, P.A. \& Webb, T. 1983. Dynamic plant ecology: the spectrum of vegetation change in space and time. Quaternary science review 1, 153-175. DOI: 10.1016/02773791(82)90008-7
Dorner, B.; Lertzman, K. \& Fall, J. 2002. Landscape pattern in topographically complex landscapes: issues and techniques for analysis. Landscape Ecology 17, 729-743. DOI: 10.1023/A:1022944019665

Drăgut, L.; Walz, U. \& Blaschke, T. 2010. The third and fourth dimensions of landscape: towards conceptual models of topographically complex landscapes. Landscape Online 22, 1-10. DOI: 10.3097/LO.201022

Fletcher, R.J. Jr; McCleery, R.A.; Greene, D.U. \& Tye, C.A. 2016. Integrated models that unite local and regional data reveal larger-scale environmental relationships and improve predictions of species distributions. Landscape Ecology 31, 1369-1382. DOI: 10.1007/s10980-015-0327-9

Haila, Y. 2002.Scaling environmental issues: problems and paradoxes. Landscape and Urban Planning 61, 59-69. DOI: 10.1016/S0169-2046(02)00102-0

Hall, O.; Hay, G.J.; Bouchard, A. \& Marceau, D.J. 2004. Detecting dominant landscape objects through multiple scales: An integration of objectspecific methods and watershed segmentation. Landscape Ecology 19, 59-76. DOI: 10.1023/B:LA ND.0000018371.43447.1f

Hoechstetter, S.; Walz, U.; Dang, L.H. \& Thinh, N.X. 2008. Effects of topography and surface roughness in analyses of landscape structure $-A$ proposal to modify the existing set of landscape metrics. Landscape Online 3, 1-14. DOI: 10.3097/ LO.200803

Kachanoski, R.G. 1988. Processes in soil-from Pedon to landscape. In: Rosswall, T.; Woodmansee, R.G. \& Risser, P.G. (eds.): SCOPE 35. Scales and Global Change: Spatial and Temporal Variability in Biospheric and Geospheric Processes. Wiley, UK. 
Kennedy, R.S.H.; Spies, T.A. \& Gregory, M.J. 2008. Relationships of dead wood patterns with biophysical characteristics and ownership according to scale in Coastal Oregon, USA. Landscape Ecology 23, 55-68. DOI: 10.1007/ s10980-007-9164-9

Khoroshev, A.V. \& Aleshchenko, G.M. 2008. Methods to identify geosystems with a commonalty of intercomponent relationships. Geography and Natural Resources 29(3), 267-272. DOI:10.1016/j. gnr.2008.09.012

Khoroshev, A.V. 2003. Spatial organization of landscapes as a function of the block structure of territories. Moscow University Vestnik, series 5, Geography 1, 9-15 (in Russian).

Khoroshev, A.V.; Eremeeva, A.P. \& Merekalova, K.A. 2013. Evaluation of intercomponent linkages in the steppe and taiga landscapes in relation to modifiable spatial unit. Proceedings of Russian Geographical Society 145(3), 32-42 (in Russian).

Khoroshev, A.V.; Merekalova, K.A. \& Aleshchenko, G.M. 2007. Multiscale organization of intercomponent relations in landscape. In: Dyakonov, K.N.; Kasimov, N.S.; Khoroshev, A.V. \& Kushlin, A.V. (eds.): Landscape Analysis for Sustainable Development. Theory and Applications of Landscape Science in Russia. Alex Publishers: Moscow.

King, R.S.; Richardson, C.J.; Urban, D.L. \& Romanowicz, E.A. 2004. Spatial dependency of vegetation environmental linkages in an anthropogenically influenced wetland ecosystem. Ecosystems 7, 7597. DOI: 10.1007/s10021-003-0210-4

Legendre, P., \& Legendre, L., 1998. Numerical Ecology. Elsevier: Amsterdam, 853 p. DOI: 10.1016/S03043800(00)00291-X

Legendre, P. 1993. Spatial autocorrelation: trouble or a new paradigm. Ecology 74, 1659-1673. DOI: $10.2307 / 1939924$
Litaor, M.I.; Seastedt, T.R. \& Walker, D.A. 2002. Spatial analysis of selected soil attributes across an alpine topographic/snow gradient. Landscape Ecology 17, 71-85. DOI: 10.1023/A:1015216400909

Lookingbill, T. \& Urban, D. 2004. An empirical approach towards improved spatial estimates of soil moisture for vegetation analysis. Landscape Ecology 19, 417-433. DOI: 10.1023/B:LAND.0000 $030451.29571 .8 \mathrm{~b}$

Malanson, G.P. 1996. Modelling forest response to climatic change: issues of time and space. In: Majumdar, S.K.; Miller, E.W. \& Brenner, F.J. (eds.): Forests - a global perspective. Pennsylvania Academy of Sciences; Easton.

Malanson, G.P.; Zimmerman, D.L.; Kinney, M. \& Fagre, D.B. 2017. Relations of alpine plant communities across environmental gradients: multilevel versus multiscale analyses. Annals of the American Association of Geographers 107 (1), 41-53. DOI: 10.1080/24694452.2016.1218267

McGarigal, K. \& Cushman, S.A. 2005. The gradient conceptoflandscapestructure.In:Wiens,J.\&Moss, M. (eds.): Issues and Perspectives in Landscape Ecology. Cambridge University Press; Cambridge. DOI: $10.1017 /$ CBO9780511614415.013

McGarigal, K.; Zeller, K.A. \& Cushman, S.A. 2016. Multi-scale habitat selection modeling: introduction to the special issue. Landscape Ecology 31, 1157-1160. DOI: 10.1007/s10980016-0388-4

Messier, C. \& Puettmann, K.J. 2011. Forests as complex adaptive systems: implications for forest management and modeling. L'Italia Forestale e Montana 66(3), 249-258. DOI: 10.4129/ ifm.2011.3.11

Miguet, P.; Jackson, H.B.; Jackson, N.D.; Martin, A.E. \& Fahrig, L. 2016. What determines the spatial extent of landscape effects on species? Landscape Ecology 31, 1177-1194. DOI 10.1007/ s10980-015-0314-1 
Musio, M.; von Wilpert, K. \& Augustin, N.H. 2007. Crown condition as a function of soil, site and tree characteristics. European Journal of Forest Research 126, 91-100. DOI: 10.1007/s10342006-0132-8

Neef, E. 1967. Die theoretischen Grundlagen der Landschaftslehre. Haack; Gotha, Leipzig. Also in: Wiens, J.A.; Moss, M.; Turner, M.G. \& Mladenoff, D.J. (eds.) 2006. Foundation Papers in Landscape Ecology. Columbia University Press; New York.

Oline, D. \& Grant, M.C. 2002. Scaling patterns of biomass and soil properties: an empirical analysis. Landscape Ecology 17, 13-26. DOI: 10.1023/A:1015276723949

O'Neill, R.V. 1988. Hierarchy theory and global change. In: Rosswall, T.; Woodmansee, R.G. \& Risser, P.G. (eds.): SCOPE 35. Scales and Global Change: Spatial and Temporal Variability in Biospheric and Geospheric Processes. Wiley, UK. DOI: 10.1002/esp.3290150410

Perry, G.L.W. \& Enright, N.J. 2002. Spatial modelling of landscape composition and pattern in a maquis-forest complex, Mont Do, New Caledonia. Ecological Modelling 152, 279-302. DOI: 10.1191/0309133306pp469ra

Peters, D.P.C.; Pielke, R.A. Sr; Bestelmeyer, B.T.; Allen, C.D.; Munson-McGee, S. \& Havstad, K.M. 2004. Cross-scale interactions, nonlinearities, and forecasting catastrophic events. Proceedings of the National Academy of Sciences of the USA 101, 15130-15135. DOI: 10.1073/pnas.0403822101

Puzachenko, Yu.G. 1986. Space-time hierarchy of geosystems from the standpoint of fluctuation theory. In: Issues in Geography. Geosystem modeling, 127. Mysl'; Moscow. (in Russian)

Sebastiá, M-T. 2004. Role of topography and soils in grassland structuring at the landscape and community scales. Basic and Applied Ecology 5, 331-346. DOI: 10.1016/j.baae.2003.10.001
Shugart, H.H. 1999. Equilibrium versus nonequilibrium landscapes In: Wiens, J.A. \& Moss, M.R. (eds.): Issues in Landscape Ecology. 5th IALEWorld Congress; Snowmass, CO, USA.

Sochava, V.B. 1978. Introduction to the theory of geosystems. Nauka; Novosibirsk. (in Russian)

Solnetsev, N.A. 1948. The natural geographic landscape and some of its general rules. In: Proceedings of the Second All-Union Geographical Congress, vol 1. OGIZ; Leningrad (in Russian). Also in: Wiens, J.A.; Moss, M.; Turner, M.G. \& Mladenoff, D.J. (eds.) 2006. Foundation Papers in Landscape Ecology. Columbia University Press; New York.

Solon, J. 1999. Integrating ecological and geographical (biophysical) principles in studies of landscape systems. In: Wiens, J.A. \& Moss, M.R. (eds.): Issues in Landscape Ecology. 5th IALEWorld Congress; Snowmass, CO, USA.

Turnbull, L.; Wainwright, J.; Brazier, R.E. \& Bol, R. 2010. Biotic and abiotic changes in ecosystem structure over a shrub-encroachment gradient in the southwestern USA. Ecosystems 13, 12391255. DOI: 10.1007/s10021-010-9384-8

Turner, M. \& Gardner, R.H. 2015. Landscape ecology in theory and practice. Pattern and process. Springer; Berlin, Heidelberg, New York.

Vasconcelos de, M.J.P.; Zeigle, B.P. \& Graham, L.A. 1993. Modeling multiscale spatial ecological processes under the discrete-event systems paradigm. Landscape Ecology 8, 273-286. DOI: 10.1007/BF00125133

Weaver, K. \& Perera, A.H. 2004. Modelling land cover transitions: A solution to the problem of spatial dependence in data. Landscape Ecology 19, 273-289. DOI: 10.1023/B:LAND.0000030418 $.90245 .4 \mathrm{~b}$ 
Wilcox, B.P.; Breshears, D.D. \& Allen, C.D. 2003. Ecohydrology of a resource-conserving semiarid woodland: effects of scale and disturbance. Ecological Monographs 73(2), 223-239. DOI: 10.1890/0012-9615(2003)073[0223:EOARSW]2. $0 . \mathrm{CO} ; 2$

Wu, J. \& David, J.L. 2002. A spatially explicit hierarchical approach to modelling complex ecological systems: theory and applications. Ecological Modelling 153, 7-26. DOI: 10.1016/ S0304-3800(01)00499-9

Wu, J.; Jelinski, D.E.; Luck, M. \& Tueller, P.T. 2000. Multiscale analysis of landscape heterogeneity: scale variance and pattern metrics. Geographic Information Sciences 6, 6-19. DOI: 10.1080/10824000009480529

Wu, X.B., \& Archer, S.R. 2005. Scale-dependent influence of topography-based hydrologic features on patterns of woody plant encroachment in savanna landscapes. Landscape Ecology 20, 733742. DOI: 10.1007/s10980-005-0996-x

Yao, J.; Peters, D.; Havstad, K.; Gibbens, R. \& Herrick, J. 2006. Multiscale factors and longterm responses of Chihuahuan desert grasses to drought. Landscape Ecology 21, 1217-1231. DOI: 10.1007/s10980-006-0025-8

Zeng, Y. \& Malanson, G.P. 2006. Endogenous fractal dynamics at alpine treeline ecotones. Geographical Analysis 38, 271-287. DOI: 10.1111/j.1538-4632.2006.00686.x

Zhang, C.; Wu, J.; Grimm, N.B.; McHale, M. \& Buyantuyev, A. 2013. A hierarchical patch mosaic ecosystem model for urban landscapes: Model development and evaluation. Ecological Modelling 250, 81-100. DOI: 10.1016/j. ecolmodel.2012.09.020 